\title{
Poverty amongst the Elderly in South Korea: The Perception, Prevalence, and Causes and Solutions
}

\author{
Sun Jae Lee
}

\begin{abstract}
When attempting to volunteer with a senior citizen welfare center in Seoul, I was originally turned away due to my age. Once persuading the center to allow me to volunteer, I began to realize that there was a bigger issue at hand than simply assisting the elderly. The issue of the high rate of poverty amongst these individuals and many others across South Korea was alarming and motivated me to investigate further into the root cause of the issue, what is currently being done to combat it, and what can be done further to lessen or eradicate this problem. Nearly half of South Koreans at the of 65 or more, are living in poverty; which is the highest among member nations of Organization for economic Co-operation and Development (OECD) [1]. While almost 60 percent of their total income is earned, 15 percent rely on the national pension, and South Korea was ranked the second lowest among all members of the OECD in terms of spending for the welfare of the elderly [1]. With the increasing senior population in South Korea and the rising rate of poverty within that population, the government and general public must move towards accommodating their needs through more agencies and organizations designed to assist them as well as a more established welfare system. Not only this, but there must be a shift in cultural views that will allow the financial responsibility to not be put upon families, but rather become a part of the government's concern for its population, young and old.
\end{abstract}

Index Terms—Elderly poverty, South Korea.

\section{INTRODUCTION}

Of all the nations that are a part of the Organization for Economic Co-operation and Development (OECD), The OECD reports that South Korea has the highest rate of elderly poverty, with almost half of its citizens at the age of 65 or more living in relative poverty; "relative poverty" being defined as falling below $50 \%$ of the average household income [1]. Seniors desperately try to work for as long as they can to earn money to support themselves, and consequently, Korea has an average retirement age of 70, meaning the number of those who work past retirement in South Korea is twice the number than other OECD countries [1].

Part of this economic disparity between the elderly and the younger generation can be attributed to the lack of preparations for a proper pension system by the South Korean government [2]. Other factors that contribute to the economic disparity include a lack in jobs offered for the elderly to earn their own income, as well as weakening bonds (i.e. less financial support provided) within families [3].

Manuscript received July 6, 2013; revised September 22, 2013.

Sun Jae Lee is with the Korea International School, South Korea (e-mail: sjlee15@student.kis.or.kr).
For decades, the government did not need a pension system strong enough to support all Korean seniors with adequate money because the Confucian system of Korea ensured that the elderly could always depend on family for financial support. In 1980, child-to-parent monetary transfers accounted for $72 \%$ of the total income of elderly people. However, over the years, reluctance to support has clearly increased drastically, and that $72 \%$ dropped to a mere $31 \%$ in 2003 [4]. Simply expecting families to support the elderly is not a viable solution anymore-other measures must be taken.

When compared to the other OECD nations, South Korea's government spends the least on welfare for senior citizens, second only to Mexico's. Accordingly, the public pension system provided by the government supports less than a third of the senior citizens in Korea [1]. Nevertheless, parents still continue to financially support their children until marriage, which keeps this cycle of the elderly falling into poverty going. Parents go bankrupt trying to manage both their and their children's economical needs, and because of the slowly deteriorating Korean Confucian culture, their children mostly do not provide that same assistance [5].

With the increasing senior population in South Korea and the rising rate of poverty within that population, the government and general public must move towards accommodating their needs through more agencies and organizations designed to assist them as well as a more established welfare system. Not only this, but there must be a shift in cultural views that will allow the financial responsibility to not be put upon families-as the Confucian culture of Korea encourages-but rather to become a part of the government's concern for its population, young and old.

\section{Status OF FinANCIAL SUPPORT FOR THE ElDERLY LIVING IN SOUTH KOREA}

In the past, the majority of financial support for elderly was provided by families and close relatives. Due to Korea's Confucian culture, for decades it has been the norm for sons and daughters to economically support their parents after they retired and did not have means to earn enough money to live on. The government, knowing this, took advantage of this financial give-and-take relationship, and took the liberty of not preparing any extra measures to provide the elderly with pensions because they relied completely on relatives of the Korean elderly. However, Tai-Hyun Kim, a family relations specialist at Sung Shin University, and Gene H.Y. Yoon, a gerontologist at Yonsei University [6], predicted that with modernization (which correlates with trends in urbanization and industrialization), tension and gaps between generations will occur and that the elderly's roles in society 
would diminish, resulting in their having a lower status amongst families. This could lead to less levels of respect for the elderly or less responsibility for the younger generations to support their elders.

Their predictions were accurate. As the formerly strong Confucian culture of Korea began to disintegrate, so did obligatory financial support for parents and grandparents, meaning that the elderly needed other means of acquiring the money they needed to support themselves. The Korean government, frantic when it found out the bastion that they had solely depended on to be the substitute of old-age pensions had fallen apart, had to begin taking their own measures to support the elderly relatively late. In 1982, the Korean Aging Policy Act was published-the only document they had outlining a social policy whose purpose was to provide economic support for the aged. In 1989, the first multipurpose welfare center for the poor elderly without relatives was installed, and was entirely funded by the city. However, the biggest programs that were created on the behalf of the Korean elderly were the Medicare program and the National Pension Act. The Medicare program begun in 1984, and through it, all elders were entitled to a free health examination every other year. The National Pension Act was amended in 1989, and provided pensions for unemployed Koreans over the age of sixty [6].

Currently, the national pensions provided by the government are still the main means of money provided to Koreans. The NBLSS and the Elderly Pension Scheme are two programs that provide income support for the low-income elderly in Korea. NBLSS is a program that guarantees the minimum standard of living for people. To be qualified to receive assistance from NBLSS, elderly must earn less money that the minimum cost of living determined by the Ministry of Health and Welfare, as well as have no immediate family members capable of supporting them. The Elderly Pension Scheme supports elderly that are not qualified to be supported by the National Pension Scheme in its criteria of requiring a contribution period. The Elderly Pension Scheme is financed by the national treasury and provides pensions for those of ages 65 and over and is eligible for NBLSS [5].

Another pension provided by the government is the "basic old-age pension system," which was introduced in 2008 and provides support for elders that fit the income criteria. This provides $5 \%$ of Koreans' average wage for $70 \%$ of the elderly. Although this system is meant to solve the problem of elderly poverty, because resources are "spread out thinly over a large segment of the older population" instead of focusing on solving the problem permanently for a small fraction, it does little to reduce poverty among the elderly [4].

On a more practical note, the government has also been working to provide the elderly with more job opportunities so that they can earn their own money and profit. In the Aged Employment Promotion Act 2003, 160 categories of jobs deemed appropriate for elderly were listed and employers were encouraged to hire a certain percent of aged workers for these jobs in return for receiving South Korean government subsidies [5]. These subsidies would fund costs that would come with increasing the number of elders, including fees of hiring aged workers, maintaining retired workers, and employing unemployed workers who have gone through re-employment training.

According to Reference [5], currently $46.2 \%$ of Korean elders are financially self-reliant and do not receive any financial support from relatives. $192 \%$ of Korean elders received financial support from non-co-residing children, children's spouses, or grandchildren, and $20 \%$ of Korean elders received financial support from co-residing children, children's spouses, or grandchildren. However, only $6.2 \%$ of elders receive adequate support from national social security schemes or social organizations.

\section{RoOt CAUSES OF ELDERLy POVERTY}

There is no single, main cause for the phenomena that exists in South Korea. One of the many causes that contributed to the high rate of elderly poverty in Korea is the lack of preparations for a proper pension system by the South Korean government [2]. The old-age pension, otherwise known as the National Pension Scheme was installed in 1988. Because it is so young, it has not had much time to sink its roots into the soil and grow in the aspects of both reaching a wide audience as well as being beneficial. Although the pension was introduced to financially support low-income senior citizens, it does not make a significant difference in the incomes of the elderly. Because this pension was introduced so late, benefits can only amount to an addition of 94,000 won (83 U.S. dollars) per month--the amount of money a person would spend per day. Also, according Reference [4], only $6.2 \%$ of the elderly rely on elderly pension schemes provided by the government or support given by social organizations.

Another reason the problem of elderly poverty exacerbated in the past decade is inherent within the majority of Korean families. In recent years, there has been a sharp decline in elders' economic dependence on children. Not only has respect for elders within families diminished due to the development of healthy technologies, development of economic technologies, the expansion of mass education, and urbanization [3]; the weakening of Confucian influence and intrafamilial bonds has also had a profound impact. According to Reference [6], during the Japanese colonial period and the Korean War, the Korean economy was ruined. Couples used the majority of their budgets on the educations or marriages of their children, with the natural expectations that their children would, in turn, support them in later years (to provide them with parental care, which has always been necessary in Confucian culture). Therefore, children are the main source of elders' money, and as a result, they grow extremely dependent upon their kids. Reluctance to support parents on the children's part stops the single, most important means of income for elders, and this means aged Koreans have no source of money and fall into poverty. Today, $41.7 \%$ of Korean elders credit their poverty to the ample amount of money they dedicated to supporting their children [5].

However, according to Sung-Jae Choi [3], the most significant factor contributing to elderly poverty in Korean society is mandatory retirement. In Korea, the mandatory retirement age for most employment contracts is 55 [7]. Although Korean citizens have the right to take whichever 
job possible for them and earn as much money as they can, once they reach their mandatory retirement age, they cannot"work more" or "work less" to earn more money after retirement. He reports that, after retirement, the most common and major source of income comes from retirement benefits given under the Labor Standards Act. Although these retirement benefits are the only thing provided to support the elderly, they are not sufficient to maintain a minimum living standard. Therefore, without additional support, a large percentage of Korea's elderly are forced into poverty and do not have the measures needed to get out of it.

\section{PERCEPTION VS REALITY}

Through reports and research that already exist, it is hard to deny that the population of elderly citizens living in poverty is on the rise. Roughly one in two elderly people in Korea is living in poverty, and Korea has the highest elderly household poverty rate among OECD member countries [1]. However, when an online survey entitled "Survey Regarding Elderly Poverty" was conducted by the author via Survey Monkey with 217 Korean citizens under the age of 50, results showed that many people in Korea who could not experience this catastrophe first-hand underestimated the prevalence of this issue. $24.0 \%$ of Koreans from the age of 10 to 19 said that they felt that the severity of elderly poverty should be rated 7 out of $10.32 .4 \%$ of Koreans from the age 20 to 29 felt that it should be rated 8 out of $10.44 .4 \%$ of Koreans from the age of 30 to 39 and $48.6 \%$ of Koreans from the age of 40 to 50 also thought it should be rated 8 out of 10 .

Koreans of different age groups were surveyed to determine what they thought was the most significant factor contributing to the rise of elderly poverty in recent years, and different age groups produced different results. Koreans from ages 10 to 19 believed that the biggest reason so many elderly people were falling into poverty was due to the lack of support they received from their families, with $35.2 \%$ of those surveyed voting for this option. However, ironically, at the same time, amongst those from the age group of 30 to 39 , not a single one of the survey-takers thought so. Instead, approximately $38.9 \%$ of them felt that elderly poverty became as big a problem as it did due to the excessively high investments of money by the elderly into their family. Amongst Koreans between the ages of 20 and 29, the majority, of which was comprised of $24.3 \%$, believed that the main cause was the elderly not having saved up enough money to sufficiently support themselves after retirement. Citizens from ages 40 to 50 also believed that the severity of elderly poverty has stemmed from the elderly investing too much money into family, but a whopping $54.1 \%$ took that stance in this age group. According to Reference [5], 41.7\% of the impoverished elderly said that the greatest factor that contributed to their economic state was due to the extensive support they provided for their children's well-being. $28.5 \%$ of the poor Korean elders said that their economic state was instead due to their inability to save up money to support them after retirement.

When given four options of possible solutions or measures for Korea and its government to take to alleviate the prevalent issue of elderly poverty--putting a policy forward that encourages children donating to their elderly parents, having the government raise pensions, having more jobs provided, and decreasing taxes, different age groups had different preferences upon which approaches would have efficacy. From citizens of ages 10 to $19,44.0 \%$ felt that the proper measures to take were to reserve more jobs especially for seniors. $51.4 \%$ of Korean citizens between the ages of 20 and 29 held the same opinion. By contrast, a whopping $50.0 \%$ of citizens between the ages of 30 and 39 felt that the right solution was to make sure the government would provide higher pensions. But alas, $64.9 \%$ of Koreans between the ages of 40 and 50 also believed that the only way to fix this prevalent issue was by providing more jobs that elderly would be able to take and secure income.

In reality, as of now, particular measures have proven to be more effective than others. $25.8 \%$ of the income that elderly households receive comes from private transfers from relatives or friends, and only $12.8 \%$ is accounted for by public pensions provided by the government. This shows that the majority of the elderly in Korea depends more on "informal safety nets" instead of the insufficient funds that the government provides [7]. This suggests that measures to increase government pensions must be taken over policies to make monetary transfers within families mandatory. In terms of providing jobs, policies such as the Aged Employment Promotion Act 2003 are already being implemented to achieve this goal, and have provided incentives to incorporate more elders into the country's workforce. However, more policies that would provide the elderly with more jobs could be effective.

Another question that Koreans were asked was what they thought the average Korean household income would be in millions of Korean won (KRW). The results are as follows: for Koreans between the ages of 10 and 19, 20 million KRW to 30 million KRW and 30 million to 40 million KRW both received $28.0 \%$ of the votes, which also happened to be the majority. For those between the ages of 20 and 29, 29.8\% believed that the average household income fell between 20 and 30 million KRW. $38.9 \%$ of survey takers between the ages of 30 and 39 believed that the average household income was between 30 and 40 million KRW, as did $37.8 \%$ of survey takers between the ages of 40 and 50 . In reality, the total household income is 3,842 thousand KRW per month, which is approximately 38.42 million KRW [7]. Although all four age groups came close to the actual value, the two older age groups chose the correct range most likely because of their older ages and the greater exposure to the reality of economics within the home they received as adults.

\section{RECOMMENDATIONS FOR SOLVING ELDERLY POVERTY DILEMMA}

With a variety of factors that contribute to the rise in poverty over the past decade, there also are numerous solutions that can be offered. One approach is to increase job opportunities for the elderly. According to Statistics Korea, $58.5 \%$ of Koreans between 55 and 79 years old are looking for jobs. Of these people, $59.4 \%$ said that they wanted to work to financially support themselves because they had not prepared beforehand for their post-retirement lives. 
Providing more jobs for the elderly is the only way to supply more elderly with a steady flow of money for them to supportthemselves. Although the Aged Employment Promotion Act is already being enforced, the government can go to further measures to reserve jobs for the elderly or to give people more time before snatching their jobs away. The Korean government could work to raise the retirement age in Korea because, as statistics show, whereas retirement is enforced because elders are thought to be unfit to work, the elderly look for other jobs to take as soon as they retire. The Korean government could go through the process that the Japanese government is planning to right now: Japanese legislators are trying to limit the growing welfare costs, change the demographics of the working population, and control public debt through a reform that will rise the retirement age in Japan. These measures would also have the same effects if applied to Korea, which is essentially in the same situation as Japan due to its similarly rapidly-aging population. The government could also work to pass more policies having to do with setting apart jobs especially for retired seniors. The government could hire elderly workers and pay them with money accumulated from taxes, create jobs for elders themselves, or provide benefits for organizations that provide jobs for those over the age of fifty-five. This could actively involve more elders in the Korean workforce or provide incentives for other companies not under the power of the government to. According to a study, if a government program used to give aged people jobs was fully implemented, the elderly poverty rate would drop by more than $6 \%$.

Also, the government could begin providing different benefit systems that would be more effective in today's society or put more emphasis on the benefit programs that have shown positive effects. However, to do this, the government would have to allocate more funds in the area of supporting the elderly. The welfare expenditure of the Korean government accounts for only 9\% of its GDP (gross domestic product), whereas the OECD average for welfare expenditure is $19 \%$--an astounding $10 \%$ difference [1]. Korea's government should adjust its priority list of benefit programs, and cut spending in areas such as free daycare for children and instead dedicate more money into providing elderly with free health care, not requiring them to pay taxes or fees for public transportation, or by supporting elderly welfare centers with more funds. This would allow Korea's welfare expenditure to climb, and it should be altered until it at least reaches the OECD average welfare expenditure.

Another thing desperately in need of financial support is the old age pension. Koreans over the age of sixty-five are eligible for this pension, but they receive a mere 94,000 won every month--barely enough to pay for a day's necessities. It is true that the pension is still fairly young and still needs time to take a significant impact, but a greater allocation of money in this issue would expedite this process. According to Reference [1], Korea has four times the average OECD country poverty rate: $49 \%$ of the people that are sixty-five years or older struggle to meet their day-to-day living expenses. A higher pension would decrease this rate substantially, and take measures to actually solve the problem of elderly poverty.

\section{CONCLUSION}

Without the efforts to reduce the amount of elderly citizens living in poverty in South Korea, the problem is likely to worsen. As South Koreans are moving away from the traditional and Confucianism way of thinking in regards to the elderly, financial responsibility for elderly citizens must be addressed by the government, local and national. At an elderly poverty rate of $49.1 \%$, it is about time that the Korean government realizes how rapidly this situation is worsening and does something in response. Many solutions have been posed and are possible to execute; however, none come without some kind of sacrifice. The government must realize that although there are inevitably other social and economic problems in Korea that must be dealt with, the diminishing economic position of the elderly is not one to be overlooked. As Korea grows into an increasingly aged population, the government needs to tend to the issue of elderly poverty and learn how to counter it before it becomes a more prevalent problem nearly impossible to solve.

\section{REFERENCES}

[1] Poverty worsening among South Korea's aged people. The Nation. The Korean Herald. [Online]. Available: http://www.nationmultimedia.com/opinion/Poverty-worsening-among -South-Koreas-aged-people-30185727.html.

[2] J. Power. (28 May 2012). How can Korea end poverty. The Korean Herald VOICE. [Online]. Available: http://nwww.koreaherald.com/view.php?ud=20120528000462.

[3] S.-J. Choi, "Aging and social policy in Korea," Korea Journal of Population and Development, vol. 25, no. 1, pp. 1-25, 1996.

[4] P. J. Cook and E. H. Kim, "Response of family elder support to changes in the income of the elderly in Korea," 2010 Annual Meeting of the Population Association of America, 2010.

[5] The Legislative Council Commission. (16 June 2005). Legislative Council Secretariat. Hong Kong. By Michael Yu. N.p. [Online]. Available:

http://www.legco.gov.hk/yr04-05/english/sec/library/0405in34e.pdf.

[6] H. A. Palley, "Social policy and the elderly in South Korea: Confucianism, modernization, and development," Asian Survey, vol. 32, no. 9, pp. 787-801, 1992.

[7] Household income and expenditure trends in the fourth quarter and in 2011. Statistics Korea. N.p. [Online]. Available: http://kostat.go.kr/portal/english/news/1/7/index.board?bmode=read.

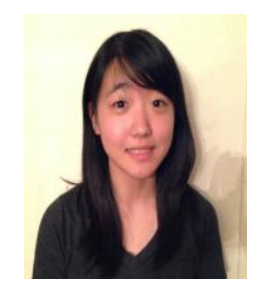

Sun Jae (Jasmine) Lee was born in Seoul, South Korea. She attends Korea International School as a high scholar and as part of the class of 2015. She has been part of various internship programs during her high scholar career. She has been part of the Joongang Ilbo Los Angeles reporter program, an economic magazine reporter team (called "The Hermes"), and in the editor team for a student magazine called "Between the Lines." She is incredibly interested in research regarding poverty, both inside and outside of Korea, as well as research regarding psychological issues and the impact that they have.

Ms Lee is a member as well as an officer in the National Honor Society at her high school. She has had an article printed in the December edition of the Los Angeles Joongang Ilbo and regularly works as a student reporter for that publication. 